\title{
Randomised controlled trial of respiratory system compliance measurements in mechanically ventilated neonates
}

Ben J Stenson, Rebecca M Glover, Rosalie A Wilkie, Ian A Laing, William O Tarnow-Mordi

\begin{abstract}
Aim-To determine whether outcomes of neonatal mechanical ventilation could be improved by regular pulmonary function testing.

Methods-Two hundred and forty five neonates, without immediately life threatening congenital malformations, were mechanically ventilated in the newborn period. Infants were randomly allocated to conventional clinical management (control group) or conventional management supplemented by regular measurements of static respiratory system compliance, using the single breath technique, with standardised management advice based on the results.

Results-Fifty five (45\%) infants in each group experienced one or more adverse outcomes. The median (quartile) durations of ventilation and oxygen supplementation were $5(2-12)$ and $6(2-34)$ days for the control group, and 4 (2-9) and 6 (3-36) days for the experimental group (not significant). On post-hoc secondary analysis, control group survivors were ventilated for 1269 days with a median (quartile) of 5 (2-13) days, and experimental group survivors were ventilated for 775 days with a median (quartile) duration of $3(2-8)$ days $(p=0.03)$.

Conclusions-Although primary analysis did not show any substantial benefit associated with regular measurement of static respiratory system compliance, this may reflect a type II error, and a moderate benefit has not been excluded. Larger studies are required to establish the value of on-line monitoring techniques now available with neonatal ventilators. (Arch Dis Child Fetal Neonatal Ed 1998;78:F15-F19)
\end{abstract}

Keywords: pulmonary function testing; mechanical ventilation; on-line monitoring; respiratory system compliance

Techniques and equipment for mechanically ventilating immature infants have evolved rapidly over the past three decades. Infants no longer die of respiratory disease as often as they used to. The improvement in survival of the smallest infants has shifted our focus from mortality to morbidity. The challenge now is to reduce the incidence of chronic lung disease and cerebral damage and the associated costs of prolonged hospital stay, but there is little to suggest that their incidence is falling. The mean duration of ventilation and hospital stay of the smallest infants may be increasing rather than decreasing. ${ }^{12}$ Lung damage from ventilation is an important contributor to these problems, and volutrauma from lung overdistension is an underlying mechanism of this. ${ }^{34}$ Traditionally, neonatal ventilators are pressure limited rather than volume limited, and it may be that closer attention to the pressure volume characteristics of the lungs would permit more appropriate individualisation of ventilator settings.

Computed systems for measuring the pressure volume characteristics of the lungs in mechanically ventilated infants are now safely and readily applicable. They are in use in many centres, but despite their expense, there is at present no substantial evidence that they improve important neonatal outcomes. We postulated that regular measurements of static respiratory system compliance, used as a guide to ventilator management, could reduce the prevalence of major adverse neonatal outcomes and shorten the duration of ventilator dependence and oxygen therapy.

We conducted a randomised controlled trial comparing routine clinical management (control group) with clinical management supplemented by regular information on respiratory system compliance (experimental group), to determine whether the experimental group would have: (a) fewer adverse clinical events (defined as death before discharge, or receiving mechanical ventilation at 15 days, or breathing supplementary oxygen at 36 weeks' gestational age, or pneumothorax, or pulmonary interstitial emphysema, or pulmonary haemorrhage, or abnormal cerebral ultrasound appearances at 6 weeks' postnatal age); (b) fewer days of respiratory support by endotracheal tube; (c) fewer days in $40 \%$ oxygen; (d) fewer days in supplementary oxygen.

\section{Methods}

This study was performed in the neonatal intensive care units of the Simpson Memorial Maternity Pavilion, Edinburgh, and Ninewells Hospital, Dundee, Scotland. The study was approved by the ethics committees of both institutions. Written parental consent was obtained before inclusion of any infant in the study. All neonates receiving mechanical ventilation by endotracheal tube admitted between August 1991 and June 1993 were considered for inclusion in the study. Infants were not enrolled if it was believed by the responsible clinician that their inevitable death was 
Table 1 Clinical guidelines based on compliance data

Crs $<0.6 \mathrm{ml} / \mathrm{cm} \mathrm{H}_{2} \mathrm{O} / \mathrm{m}$ indicates very stiff lungs Crs $0.6-1.2 \mathrm{ml} / \mathrm{cm} \mathrm{H}_{2} \mathrm{O} / \mathrm{m}$ indicates moderately stiff lung

Crs $1.2-1.8 \mathrm{ml} / \mathrm{cm} \mathrm{H}_{2} \mathrm{O} / \mathrm{m}$ indicates mild to moderate lung stiffness $\mathrm{Crs}>1.8 \mathrm{ml} / \mathrm{cm} \mathrm{H}_{2} \mathrm{O} / \mathrm{m}$ indicates minimal or no lung stiffness

imminent or if a life threatening congenital abnormality was apparent in the immediate neonatal period.

Infants were randomly allocated by the opening of a sealed, numbered envelope. Randomisation was stratified by treatment centre. Respiratory system compliance was measured in infants in both groups as soon as possible after endotracheal intubation, and at least daily for the first seven days of ventilation, and twice weekly thereafter until extubation. Additional measurements were made immediately before and 3 and 12 hours after each dose of surfactant.

Static respiratory system compliance was measured using the single breath technique with the infants lying supine, after endotracheal suction, as described before. ${ }^{5-7}$ Passive expiratory flow was measured using a Fleisch $\mathrm{O}$ pneumotachograph, connected to a pressure transducer (Validyne MP $45 \pm 2 \mathrm{~cm} \mathrm{H}_{2} \mathrm{O}$ ). Airway pressure was measured using a Validyne or Furness Controls pressure transducer (0-10 $\mathrm{kPa}$ ). All respiratory system compliance results were calculated as the mean of 3-6 satisfactory breaths. Studies were only accepted as valid if they had a within study coefficient of variation between breaths of $<15 \%$. Data were corrected to crown-heel length in $\mathrm{cm}$ (measured using a tape) to give units of $\mathrm{ml} / \mathrm{cm} \mathrm{H}_{2} \mathrm{O} / \mathrm{m}$, as in our experience this has given more useful information than correction to body weight. ${ }^{67}$
Not advisable to reduce ventilator support Weaning may be justified if clinically improving

Try weaning, aim for I:E $<1: 2$, PIP $<21$, PEEP $<4$

Try weaning, aim for I:E $<1: 2$, PIP $<21$, PEEP $<4$

All aspects of the clinical management of the control group were conducted according to the normal practice in each centre. The results of the respiratory system compliance measurements were not made available to clinical staff. The experimental group were managed in the same way as the control group except that the results of each measurement were immediately entered on the blood gas recording sheet where they would be seen by the clinical staff adjusting the ventilator. Guidelines to assist the clinical staff in the interpretation of the measurements were entered on the clinical record alongside the compliance data (table 1). They were based on two previous studies using the same apparatus in the nurseries of Ninewells Hospital in Dundee and Mount Sinai Hospital in Toronto, Canada. ${ }^{67}$

No attempt was made to maintain tidal volumes within set limits. The single breath technique measures the volume expired when the subject is allowed to exhale from peak inflation down to atmospheric pressure rather than to the set positive end expiratory pressure. The expired volume measured using the technique is therefore larger than the concurrent ventilator tidal volume would be. Airway resistance values were not reported. In a small number of infants with severe bronchopulmonary dysplasia expiratory flow traces showed the need for very long set expiration times. This was

Table 2 Characteristics of infants at trial entry (data are median (range) or number (\%))

\begin{tabular}{|c|c|c|c|c|}
\hline & \multicolumn{2}{|l|}{ All infants } & \multicolumn{2}{|l|}{ Surviving infants } \\
\hline & $\begin{array}{l}\text { Control group } \\
(n=122)\end{array}$ & $\begin{array}{l}\text { Experimental group } \\
(n=123)\end{array}$ & $\begin{array}{l}\text { Control group } \\
(n=106)\end{array}$ & $\begin{array}{l}\text { Experimental group } \\
(n=104)\end{array}$ \\
\hline Birthweight (g) & $1423(580-5250)$ & $1426(452-4400)$ & $1525(640-4200)$ & $1531(592-4400)$ \\
\hline Birth length $(\mathrm{cm})$ & $40(30-57)$ & $40(29-55)$ & $41(32-57)$ & $41(30-55)$ \\
\hline Gestation (weeks) & $31(23-42)$ & $30(25-42)$ & $31(25-42)$ & $31(25-42)$ \\
\hline Gender $(M / F)$ & $62 / 60(51 \%: 49 \%)^{\star}$ & $79 / 44(64 \%: 36 \%)^{\star}$ & $52: 54(49 \%: 51 \%)^{\star}$ & $67: 37(64 \%: 36 \%)^{\star}$ \\
\hline Antenatal steroids & $37(30 \%)$ & $44(36 \%)$ & $22(21 \%)$ & $30(29 \%)$ \\
\hline Initial Crs successful & $94(77 \%)$ & $102(83 \%)$ & $82(77 \%)$ & $86(83 \%)$ \\
\hline $\mathrm{Crs}\left(\mathrm{ml} / \mathrm{cm} \mathrm{H}_{2} \mathrm{O} / \mathrm{m}\right)$ & $1.5(0.5-7.9)$ & $1.4(0.5-5.6)$ & $1.5(0.5-7.9)$ & $1.5(0.6-5.6)$ \\
\hline $\mathrm{Crs}\left(\mathrm{ml} / \mathrm{cm} \mathrm{H}_{2} \mathrm{O} / \mathrm{kg}\right)$ & $0.4(0.11-1.18)$ & $0.36(0.15-1.35)$ & $0.4(0.11-1.18)$ & $0.38(0.15-1.35)$ \\
\hline Inborn & $106(87 \%)$ & $110(89 \%)$ & $94(89 \%)$ & $96(92 \%)$ \\
\hline \multicolumn{5}{|l|}{ Delivery mode } \\
\hline Vaginal & $63(52 \%)$ & $56(46 \%)$ & $52(49 \%)$ & $47(45 \%)$ \\
\hline Caesarean & $59(48 \%)$ & $67(54 \%)$ & $54(51 \%)$ & $57(55 \%)$ \\
\hline Singleton & $99(81 \%)$ & $99(80 \%)$ & $86(81 \%)$ & $83(80 \%)$ \\
\hline Apgar at 1 minute & $5(0-9)$ & $5(0-9)$ & $5(0-9)$ & $5(0-9)$ \\
\hline Apgar at 5 minutes & $8(0-9)$ & $8(1-9)$ & $8(0-9)$ & $8(1-9)$ \\
\hline
\end{tabular}

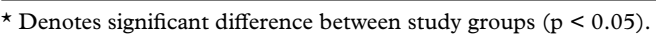

Table 3 Adverse clinical outcomes (data are number (\%) and odds ratio (95\% confidence intervals))

\begin{tabular}{|c|c|c|c|c|c|c|}
\hline & \multicolumn{3}{|l|}{ All infants } & \multicolumn{3}{|c|}{ Surviving infants } \\
\hline & $\begin{array}{l}\text { Control group } \\
(n=122)\end{array}$ & $\begin{array}{l}\text { Experimental group } \\
(n=123)\end{array}$ & Odds ratio & $\begin{array}{l}\text { Control group } \\
(n=106)\end{array}$ & $\begin{array}{l}\text { Experimental group } \\
(n=104)\end{array}$ & Odds ratio \\
\hline Death & $16(13 \%)$ & $19(15 \%)$ & $1.210(0.590-2.481)$ & & & \\
\hline Ventilator dependent day 15 & $27(22 \%)$ & $24(20 \%)$ & $0.853(0.460-1.582)$ & $25(24 \%)$ & $18(17 \%)$ & $0.678(0.344-1.335)$ \\
\hline $\mathrm{O}_{2}$ dependent 36 weeks & $24(20 \%)$ & $23(19 \%)$ & $0.832(0.436-1.588)$ & $24(23 \%)$ & $19(18 \%)$ & $0.688(0.346-1.366)$ \\
\hline Pneumothorax & $11(9 \%)$ & $9(7 \%)$ & $0.797(0.318-1.997)$ & $8(8 \%)$ & $5(5 \%)$ & $0.619(0.196-1.957)$ \\
\hline PIE & $12(10 \%)$ & $10(8 \%)$ & $0.811(0.337-1.954)$ & $7(7 \%)$ & $3(3 \%)$ & $0.420(0.106-1.671)$ \\
\hline Pulmonary haemorrhage & $10(8 \%)$ & $7(6 \%)$ & $0.676(0.249-1.837)$ & $5(5 \%)$ & $1(1 \%)$ & $0.196(0.023-1.708)$ \\
\hline Abnormal USS at 6 weeks & $14(11 \%)$ & $18(15 \%)$ & $1.612(0.744-3.492)$ & $11(10 \%)$ & $15(14 \%)$ & $1.763(0.754-4.126)$ \\
\hline Any adverse event & $55(45 \%)$ & $55(45 \%)$ & $0.985(0.596-1.630)$ & $39(37 \%)$ & $36(35 \%)$ & $0.869(0.509-1.577)$ \\
\hline
\end{tabular}


Table 4 Other outcomes (data are number (\%), odds ratio (95\% confidence intervals) and median (quartiles))

\begin{tabular}{|c|c|c|c|c|c|c|}
\hline & \multicolumn{3}{|l|}{ All infants } & \multicolumn{3}{|c|}{ Surviving infants } \\
\hline & $\begin{array}{l}\text { Control group } \\
(n=122)\end{array}$ & $\begin{array}{l}\text { Experimental } \\
\text { group }(n=123)\end{array}$ & Odds ratio & $\begin{array}{l}\text { Control group } \\
(n=106)\end{array}$ & $\begin{array}{l}\text { Experimental } \\
\text { group }(n=104)\end{array}$ & Odds ratio \\
\hline CLD & $31(25 \%)$ & $26(21 \%)$ & $0.787(0.434-1.426)$ & $29(27 \%)$ & $23(22 \%)$ & $0.754(0.402-1.415)$ \\
\hline Steroids for CLD & $23(19 \%)$ & $20(16 \%)$ & $0.852(0.440-1.650)$ & $22(21 \%)$ & $17(16 \%)$ & $0.755(0.375-1.521)$ \\
\hline Significant PDA & $29(24 \%)$ & $19(15 \%)$ & $0.568(0.308-1.114)$ & $27(25 \%)$ & $16(15 \%)$ & $0.532(0.267-1.060)$ \\
\hline Abnormal ultrasound scan week 1 & $35(29 \%)$ & $34(28 \%)$ & $0.938(0.537-1.640)$ & $25(24 \%)$ & $23(22 \%)$ & $0.920(0.482-1.754)$ \\
\hline Subependymal bleed & $9(7 \%)$ & $11(9 \%)$ & & $8(8 \%)$ & $10(10 \%)$ & \\
\hline Intraventricular bleed & $15(12 \%)$ & $13(11 \%)$ & & $10(9 \%)$ & $8(8 \%)$ & \\
\hline Periventricular bleed & $10(8 \%)$ & $5(4 \%)$ & & $6(6 \%)$ & $1(1 \%)$ & \\
\hline Days in hospital & $40(21-67)$ & $40(21-65)$ & & $47(25-75)$ & $46(24-68)$ & \\
\hline Sum days in hosptial & 6311 & 6167 & & 6101 & 5702 & \\
\hline Sum days intubated & 1429 & 1186 & & 1269 & 775 & \\
\hline
\end{tabular}
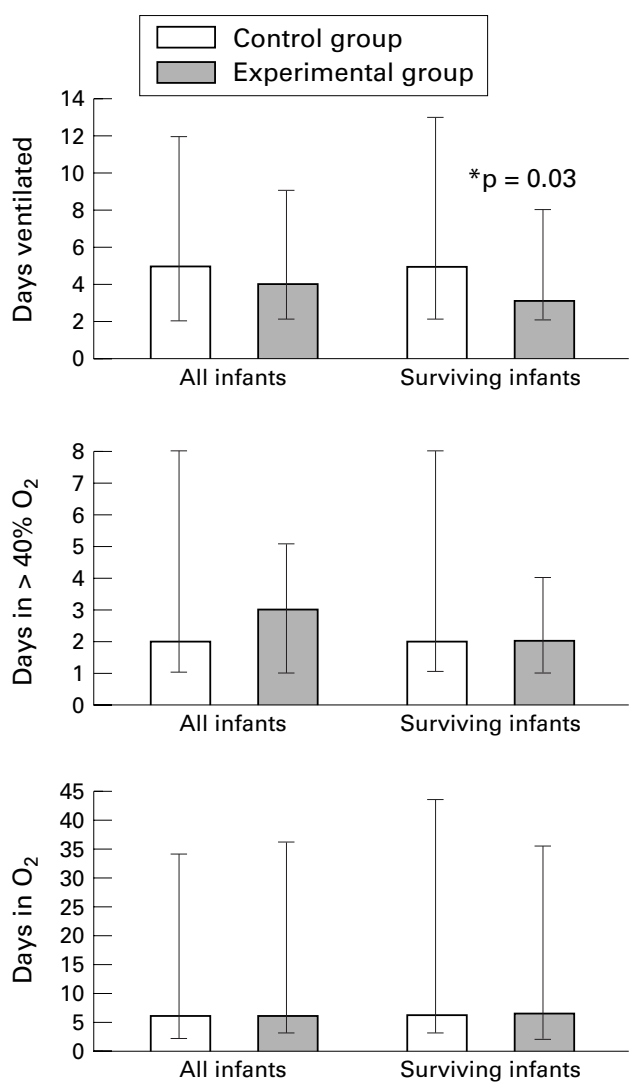

Figure 1 Days ventilated, days requiring $>40 \%$ supplemental oxygen, and days requiring any supplemental oxygen. Data are median (interquartile range).

communicated to the clinicians for those infants in the experimental group.

Because they were not blinded to the respiratory system compliance data, the research fellows were not part of the clinical team managing the infants. They attended medical rounds to explain the data and maintain a high degree of awareness about the information but did not make management decisions. Medical staff were given training about the interpretation of data both before and during the trial. It was calculated that a sample size of 104 infants in each group would yield $>80 \%$ power, to show a reduction from $40 \%$ to $20 \%$ in the combined rate of adverse clinical events at the $5 \%$ level of significance. This sample would also provide $>80 \%$ power to show a reduction in median duration of respiratory support by endotracheal tube from 7 to 4 days. Odds ratios and $95 \%$ confidence intervals were calculated for the categorical outcome vari- ables. Differences in continuous data were compared using the Mann Whitney-U test. To determine the quality of outcomes in survivors and to examine the possibility that the primary analysis was skewed by the more prolonged survival in the experimental group of infants who ultimately died, a post-hoc secondary analysis was performed on infants surviving until hospital discharge.

\section{Results}

Two hundred and forty five eligible infants were enrolled into the study. Their characteristics at study entry are shown in table 2 . The two study groups did not differ significantly in birthweight, gestational age, length, initial respiratory system compliance, frequency of antenatal steroid exposure or Apgar scores. The experimental group contained by chance a significantly greater proportion of boys than the control group. Because of air leaks around endotracheal tubes, non-linear flow/volume plots and failure to induce respiratory muscle relaxation, the compliance measurements were sometimes unsuccessful. The initial measurement at study entry was successful in 102 of 123 infants $(83 \%)$ in the experimental group and 94 of 122 controls (77\%), giving an overall success rate of $80 \%$.

The numbers of infants in each group with each adverse clinical event are given in table 3. There were no significant differences between the two groups in the frequencies of individual adverse events nor in the total number of infants in each group with any adverse event. The data for duration of oxygen supplementation and mechanical ventilation are given in fig 1. There were no significant differences between the two groups in duration of requirement for supplemental oxygen or mechanical ventilation, when considered as a whole, but survivors in the experimental group were ventilated for $40 \%$ fewer days than surviving control infants $(p=0.03)$.

Other outcomes are detailed in table 4 . There were no significant differences between the two groups in the frequencies of development of chronic lung disease (defined as requiring supplemental oxygen and having an abnormal chest $x$-ray picture at 28 days of age), or persistent ductus arteriosus requiring clinical intervention. Similar numbers of infants in the two groups were treated with steroids for chronic lung disease. There were no differences in the patterns of cranial ultrasound 
abnormalities during the first week of life. The median duration of hospital stay was identical for the two groups. Gender did not influence outcome. The percentage of infants with any adverse outcome was $45 \%$ for both boys and girls.

\section{Discussion}

In this study the introduction of measurements of static respiratory system compliance into clinical practice had no major effect on any of the primary outcome measures. This pragmatic estimate of the potential impact of respiratory function testing on major hospital outcomes does not exclude moderate benefit from this intervention, as the sample size only yielded adequate power to show a substantial difference in adverse outcomes. Until more powerful trials are conducted, caution is warranted in the rapidity with which respiratory function tests are being incorporated into routine care.

In the era of antenatal steroids and replacement surfactant a smaller proportion of infants present serious problems with ventilation than before, and it may be that by considering all ventilated infants the power of the study was blunted by the number of infants who were destined to have good outcomes. Secondary analysis suggests that there may be important potential benefits in terms of reduced duration of ventilation in surviving infants. This was not associated with shortening of hospital stay but would affect costs related to level of care required. The total duration of ventilation in survivors in the experimental group was around $40 \%$ less than that of controls. This was not a pre-specified outcome and should be regarded as a hypothesis in need of further proof rather than a definitive finding.

There was by chance a significantly increased number of boys in the experimental group. Boys seem to have worse outcomes than girls for a given birthweight or gestational age because of their increased severity of respiratory distress syndrome (RDS). ${ }^{8}$ In support of this observation, there were more boys than girls enrolled in the study overall. However, the percentage of male and female infants developing any adverse event after study enrolment was identical, indicating no overall effect of gender on the principal composite outcome measure.

Although our measurement results were written on the blood gas sheets along with an explanation of their relevance, the study protocol did not mandate that the medical staff caring for the infants must act on the basis of the study recommendations. At the time of the study these monitoring techniques were new to most of the staff and there may have been some uncertainty about the reliability or interpretation of the information. It may be that if the study was repeated, now that the technique is accepted and understood, a different result would be obtained.

The respiratory system compliance measurements were made daily, and sometimes more frequently, but perhaps this was not often enough. Without dedicated staff trained in the technique it would be impracticable for any sizeable neonatal unit to make more frequent measurements using the single breath technique, because of the time involved and expertise required. This would make the single breath technique costly to introduce into routine care. The large number of studies that were unsuccessful is likely to have diminished the power of the study. This problem is unavoidable with the single breath technique. ${ }^{9}{ }^{10}$ Nevertheless, published studies strongly support the objectivity of static measurements. These correlate well with gas exchange $^{1112}$ and reflect the course of lung disease. ${ }^{13}$ Respiratory system compliance measurements provide a measure of biochemical lung maturity that may help select infants for surfactant treatment ${ }^{7}$ and have shown potential for predicting the likelihood of successful extubation. ${ }^{14}$

An alternative would have been to use a continuous on-line monitoring technique to present waveforms and tidal volumes. Since this study began on-line monitoring has become extremely popular. Most ventilator manufacturers are building the technology into their latest ventilators or supplying it as a free standing option. There are many reasons for preferring on-line monitoring over intermittent measurements using the single breath technique. The data are readily available with no limit on the frequency of measurements and no special expertise or dedicated personnel are required to gather them. Much of the available equipment is disposable, which lessens the risk of cross infection compared with the equipment for the single breath technique which has to be cleaned between patients. Simply limiting tidal volumes to the $7-9 \mathrm{ml}$ per $\mathrm{kg}$ seen in spontaneously breathing healthy infants ${ }^{15}$ may help to prevent volutrauma. The shape of the pressure volume loop can be analysed to detect lung overinflation. ${ }^{16}$ It may be possible to use flow waveforms to adjust inspiration times individually. ${ }^{17}$ Although they are in widespread use, none of these approaches has been systematically evaluated in human infants.

On-line monitoring also has its limitations. Because they are made under dynamic conditions, the measurements are frequency dependent ${ }^{18}$ and results are influenced by the level of positive end expiratory pressure. ${ }^{19}$ Kelly et $a l^{20}$ were unable to detect improvements in dynamic compliance, and by inference, tidal volume in a population of infants treated with beractant, despite large improvements in static compliance measured simultaneously using the single breath technique that were accompanied by obvious clinical improvements. After natural surfactant treatment there are undoubtedly rapid changes in respiratory function which allow ventilator weaning, and techniques of respiratory monitoring should be able to resolve changes of this magnitude. On-line monitoring equipment typically adds around $1 \mathrm{ml}$ to the respiratory dead space of the infant. In the absence of a major leak around the endotracheal tube this might be expected to affect carbon dioxide exchange in smaller infants. ${ }^{21}$ 
There are no other published randomised trials of lung function monitoring for direct comparison. Rosen et $a l^{22}$ performed a retrospective comparison of their neonatal outcomes during two consecutive time periods. They instituted regular pulmonary function testing into routine care during the second period and found a lower incidence of pneumothoraces and intraventricular haemorrhages. The pulmonary function testing was performed frequently by three senior neonatologists who acted directly on the results and repeated the testing whenever the ventilator settings were significantly adjusted. It is likely that the increased frequency of measurement produced a greater effect. It may be that the increased frequency of assessment by a senior neonatologist alone was effective or that the expertise of the clinicians had improved by the second time period. Their study was performed in the pre-surfactant era when outcomes may have been more dependent on ventilator management than they are now. Experiences during the present study supported the idea that there may be clinical benefit to pulmonary function testing. In individual patients the data often seemed to be helpful. ${ }^{23}$ We also found during our study that junior doctors assessing respiratory system compliance clinically agreed poorly both with one another and with the measurements. ${ }^{24}$

Our study is so far the only randomised controlled evaluation of the potential of lung function testing to influence important neonatal outcomes. We have not demonstrated any conclusive benefit. On-line monitoring technology is now widespread and expensive. There is an urgent need for larger trials to establish the value of these techniques. Many units already possess sufficient ventilators with monitoring capability to permit a collaborative study of a ventilation protocol based on controlled tidal volumes, avoidance of overdistended loops, and limitation of excessive inspiratory times. Based on the data from this study a trial enrolling 800 ventilated infants of $<31$ weeks' gestation would have $>80 \%$ power to detect a fall in the incidence of death or requirement for supplemental oxygen at 36 weeks' gestation, from $49 \%$ to $39 \%$, or a reduction in the mean duration of ventilation from 15 to 10 days.

This study was funded by the Scottish Office Home and Health Department.

1 Field DJ, Milner AD, Hopkin IE, Madeley RJ. Changing patterns in respiratory distress syndrome. Pediatr Pulmono 1987;3:231-5.
2 Horbar JD, Wright EC, Onstad L. Decreasing mortality associated with the introduction of surfactant therapy: an observational study of neonates weighing 601 to 1300 grams at birth. Pediatrics 1993;92:191-6.

3 Dreyfuss D, Saumon G. Barotrauma is volutrauma, but which volume is responsible? Intensive Care Med 1992;18:139-41.

4 Parker JC, Hernandez LA, Peevy KJ. Mechanisms of ventilator induced lung injury. Crit Care Med 1993;21:131-43.

5 LeSouef PN, England SJ, Bryan AC. Passive respiratory mechanics in newborns and children. Am Rev Respir Dis 1984;129:552-6.

6 Tarnow-Mordi WO, Wilkie RA, Reid E. Static respiratory compliance in the newborn. I: A clinical and prognostic index for mechanically ventilated infants. Arch Dis Child 1994;70:F11-F15.

7 Wilkie RA, Bryan MH, Tarnow-Mordi WO. Static respiratory compliance in the newborn. II: Its potential for improving the selection of infants for early surfactant improving the selection of infants for
therapy. Arch Dis Child $1994 ; 70$ :F16-F18.

8 Farrell PM, Avery ME. State of the art HMD. Am Rev Respir Dis 1975;111:657-88.

9 Baboolal R, Kirpalani H. Measuring on-line compliance in ventilated infants using hot wire anemometry. Crit Care Med 1990;18:1070-4

10 Gappa M, Rabbette PS, Costeloe KL, Stocks J. Assessment of passive respiratory compliance in healthy preterm of passive respiratory compliance in healthy preterm
infants: A critical evaluation. Pediatr Pulmonol 1993;15:304-11.

11 Pfenninger J, Aebi C, Bachmann D, Wagner BP. Lung mechanics and gas exchange in ventilated preterm infants during treatment of hyaline membrane disease with multiple doses of surfactant (Exosurf). Pediatr Pulmonol 1992;14:10-15.

12 Dreizzen E, Migdal M, Praud JP, et al. Passive total respiratory system compliance and gas exchange in newborns with hyaline membrane disease. Pediatr Pulmonol 1989;6:2-7.

13 Dreizzen E, Migdal M, Praud JP, et al. Passive compliance of total respiratory system in preterm newborn infants with respiratory distress syndrome. F Pediatr 1988;112:778-81.

14 Balsan MJ, Jones JG, Watchko JF, Guthrie RD. Measurements of pulmonary mechanics prior to the elective extubation of neonates. Pediatr Pulmonol 1990;9:238-43.

15 American Thoracic Society, European Respiratory Society. Respiratory mechanics in infants: Physiologic evaluation Respiratory mechanics in infants: Physiologic evaluation
in health and disease. Am Rev Respir Dis 1993;147 474-96.

16 Fisher JB, Mammel MC, Coleman JM, Bing DR, Boros SJ. Identifying lung overdistension during mechanical ventilation by using volume-pressure loops. Pediatr Pulmonol 1988;5:10-14.

17 Mammel MC, Boros SJ, Bing DR, Holloman KK, Connet JR. Determining optimum inspiratory time during intermittent positive pressure ventilation in surfactant depleted cats. Pediatr Pulmonol 1989;7:223-9.

18 Kano S, Lanteri CJ, Pemberton PJ, LeSouef PN, Sly PD. Fast versus slow ventilation for neonates. Am Rev Respir Dis 1993;148:578-84

19 Gommers D, Vilstrup C, Bos JAH, et al. Exogenous surfactant therapy increases static lung compliance and cannot be assessed by measurements of dynamic compliance alone. Crit Care Med 1993;21:567-74.

20 Kelly E, Bryan H, Possmayer F, Frndova H, Bryan C. Compliance of the respiratory system in newborn infants preand postsurfactant replacement therapy. Pediatr Pulmonol 1993;15:225-30.

21 Stokes GM, Milner AD, Wilson AJ, Morgan DB, Carman PG, Oliver MR. Ventilatory response to increased dead spaces in the first week of life. Pediatr Pulmonol 1986;2:8993.

22 Rosen WC, Mammel MC, Fisher JB, et al. The effects of bedside pulmonary mechanics testing during infant mechanical ventilation: a retrospective analysis. Pediatr Pulmonol 1993;16:147-52.

23 Stenson BJ, Glover RM, Wilkie RA, Laing IA, TarnowMordi WO. Life-threatening inadvertent positive endexpiratory pressure. Am f Perinatol 1995;12:336-8.

24 Stenson BJ, Wilkie RA, Laing IA, Tarnow-Mordi WO. Reliability of clinical assessments of respiratory system compliance (Crs) made by junior doctors. Intensive Care Med 1995;21: 257-60. 